\title{
BFH-OSTM, a new predictive screening tool for identifying osteoporosis in elderly Han Chinese males
}

\author{
JiSheng Lin' \\ Yong Yang' \\ XiaoDong Zhang' \\ Zhao $\mathrm{Ma}^{\prime}$ \\ $\mathrm{Hao} \mathrm{Wu}^{2}$ \\ Yongjin $\mathrm{Li}^{3}$ \\ Xiuquan Yang ${ }^{4}$ \\ Qi Fei' \\ Ai Guo' \\ 'Department of Orthopedics, \\ Beijing Friendship Hospital, Capital \\ Medical University, Xicheng District, \\ Beijing, People's Republic of China; \\ ${ }^{2}$ Fangzhuang Community Health \\ Service Center, Fengtai District, \\ Beijing, People's Republic of China; \\ ${ }^{3}$ Tuanjiehu Community Health Service \\ Center, Chaoyang District, Beijing, \\ People's Republic of China; ${ }^{4}$ Wangzuo \\ Community Health Service Center, \\ Fengtai District, Beijing, People's \\ Republic of China
}

This article was published in the following Dove Press journal:

Clinical Interventions in Aging

31 July 2017

Number of times this article has been viewed

Purpose: To develop and validate a new clinical screening tool to identify primary osteoporosis by dual-energy X-ray absorptiometry (DXA) in two elderly Han Chinese male populations.

Methods: A cross-sectional study was conducted, enrolling 1,870 community-dwelling and 574 hospital-checkup elderly Han Chinese males aged $\geq 50$ years. All subjects completed a structured questionnaire and had their bone mineral density (BMD) measured using DXA. Using logistic regression analysis in the 1,870 community-dwelling males, we assessed the ability of numerous potential clinical risk factors to identify male with osteoporosis. Multiple variable regression analysis and item reduction yielded a final tool named the Beijing Friendship Hospital Osteoporosis Self-assessment Tool for Elderly Male (BFH-OSTM). Receiver operating characteristic (ROC) curve was generated to compare the validation of the BFH-OSTM and Osteoporosis Self-assessment Tool for Asians (OSTA) for identifying elderly male at increased the risk of primary osteoporosis in the 574 hospital-checkup males.

Results: In screening the 1,870 community-dwelling subjects with DXA, 14.2\% $(266 / 1,870)$ had osteoporosis, and a further 51.8\% $(969 / 1,870)$ had osteopenia. Of the items screened in the questionnaire, weight, height and previous history of fragility fracture were predictive of osteoporosis. A final tool (BFH-OSTM) was based on body weight and fragility fracture history only. The BFH-OSTM index (cutoff $=70$ ) had a sensitivity of $85 \%$ and specificity of $53 \%$ for identifying osteoporosis according to the WHO criteria, with an area under the ROC curve of 0.763 . The predictive value of BFH-OSTM was validated in the 574 hospital-checkup population, which performed better than OSTA.

Conclusion: The BFH-OSTM may perform well for identifying elderly male at increased risk for osteoporosis and applying it would result in more prudent use of BMD measurement by DXA, especially for Han Chinese male.

Keywords: osteoporosis, bone mineral density, male, risk factors, screening

\section{Introduction}

Osteoporosis (OP) is defined as a metabolic bone disease, characterized by low bone mass and micro architectural deterioration, which leads to increased bone fragility and a higher risk of future fractures. ${ }^{1}$ OP represents one of the major public health problems, not only in postmenopausal women, but also in elderly male. OP in male is, generally, neglected all over the world, especially in China, despite $>30 \%$ of all hip fractures occur in men and the mortality after hip fracture is significantly higher in men than in women. ${ }^{2}$ However, a person who has developed OP is nearly impossible to restore full bone strength because of irreversible structural loss in bone microarchitecture. ${ }^{3}$ The final purpose of OP intervention is to protect against fracture
Correspondence: Qi Fei; Ai Guo Department of Orthopedics, Beijing Friendship Hospital, Capital Medical University, No 95, Yong'an Road, Xicheng District 100050, Beijing, People's Republic of China Tel +861063138353 Fax +86 I0 839II029 Email spinefei@I26.com; guoaiortho@126.com

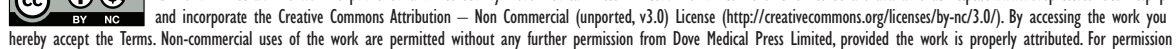
for commercial use of this work, please see paragraphs 4.2 and 5 of our Terms (https://www.dovepress.com/terms.php). 
and refracture. It is valued to predict the risk of developing OP in elderly populations and prevent the occurrence of the first fracture. Commonly, bone mineral density (BMD) is the gold standard for diagnosing OP in clinical practice, which is measured by dual-energy X-ray absorptiometry (DXA). OP is defined by the World Health Organization (WHO) as classifying the T-score of low bone mass (T-score between -2.5 and -1 ) and OP (T-score $\leq-2.5) .{ }^{4}$ In addition, the National Osteoporosis Foundation suggests that patients should accept pharmacological treatment when they have T-scores $\leq-2.5$ in the femoral neck, hip, or lumbar spine as measured by DXA. ${ }^{5}$ But, the high costs of BDM measurement by DXA and lack of refund may limit its widespread use for preliminary screening in primary hospitals, which makes this service narrowly available in the People's Republic of China. Therefore, matching approaches are required on demand to identify patients efficiently at risk for primary $\mathrm{OP}$.

So it is necessary to obtain a better way to predict OP in the People's Republic of China. Various OP screening tools have been developed by multiple organizations, such as the Osteoporosis Self-assessment Tool for Asians (OSTA), fracture risk assessment tool (FRAX), and weight-based criterion, ${ }^{6}$ but the fundamental invested to create these recommendations is mainly based on circular evidence. Besides, there is no recommendation created for elderly male in a Chinese population. Among these tools, OSTA, which is developed by Koh based on age and body weight, is a free and effective method to assess postmenopausal Asian women at the risk of having OP. ${ }^{7}$ OSTA has been found to be cost-effective for postmenopausal OP in many studies. ${ }^{8-10}$ However, the research about the validation of OSTA to identify primary OP in elderly male has seldom been published. Thus, we were motivated to develop a new screening tool for elderly Chinese male to assess the risk of DXA-determined primary OP and choose OSTA as a comparison.

The objective of this study was to develop a simple new clinical screening tool to identify primary OP in elderly male and to compare its validity with the OSTA in two elderly Han Chinese male populations.

\section{Methods}

\section{Study population}

The study population included Chinese men aged $\geq 50$ years consecutively recruited from three community health service centers (Fangzhuang, Tuanjiehu, and Wangzuo) from January 2014 to February 2016, and the Osteoporosis Clinic at Beijing Friendship Hospital from April 2016 to February 2017. We conducted a cross-sectional study, enrolling 1,870 community-dwelling and 574 hospitalcheckup elderly Han Chinese male aged $\geq 50$ years. The inclusion and exclusion criteria were listed in Table 1. Subjects with painful fragility fracture and abnormal biochemistry, including tests for renal and liver function, as well as serum levels of phosphate, total alkaline phosphatase, calcium, and thyroid-stimulating hormone, were also excluded. The study was approved by the Ethics Committee of Beijing Friendship Hospital, Capital Medical University and all subjects had signed the informed consent.

\section{BMD measurements and data obtained}

\section{via questionnaire}

The community-dwelling men came to the hospital for BMD measurements inconveniently, so they were invited to the mobile vehicle with DXA machine (Discovery Wi, QDR series, Hologic, Waltham, MA, USA) for BMD measurements of the hip and spine. The hospital-checkup males came to the Osteoporosis Clinic at Beijing Friendship Hospital for BMD measurements assessed by Hologic Discovery QDR Wi densitometer (Hologic Inc.), and all subjects were required to fill in a questionnaire by a trained interviewer to provide information regarding demographic variables and clinical risk factors for OP using a structured table. We set these potential risk factors in the questionnaire were identified from previous researches. ${ }^{11,12}$ These factors included age, height, weight, BMI, previous fracture, current smoking, consumption of three of more alcoholic drinks per day, glucocorticoids, rheumatoid arthritis, and parent fractured hip history. Height was measured with a stadiometer (Mahr GmbH, Gottingen, Germany). Weight was measured using an electronic balance scale (Tanita, Tokyo, Japan), with the subjects in lightweight indoor clothing and without shoes.

Table I Inclusion and exclusion criteria for this study

\begin{tabular}{ll}
\hline Inclusion criteria & Exclusion criteria \\
\hline Men aged $\geq 50$ years & $\begin{array}{l}\text { A history or evidence of metabolic } \\
\text { bone disease (eg, type I diabetes, } \\
\text { hyperparathyroidism or hypoparathyroidism, } \\
\text { Paget's disease, osteomalacia, renal } \\
\text { osteodystrophy, osteogenesis imperfecta) } \\
\text { History of taking antiresorptive medications } \\
\text { Evidence of rheumatoid arthritis }\end{array}$ \\
$\begin{array}{l}\text { Han Chinese } \\
\text { nestionality } \\
\text { for } \geq 20 \text { years }\end{array}$ & $\begin{array}{l}\text { History of glucocorticoid use } \\
\text { Willing to participate } \\
\text { in the study and able } \\
\text { to read the informed } \\
\text { consent form }\end{array}$ \\
& $\begin{array}{l}\text { The presence of cancer(s) with known } \\
\text { metastasis to bone } \\
\text { Evidence of significant renal impairment } \\
\text { Painful hip fracture, vertebral fracture, and } \\
\text { other osteoporotic fracture }\end{array}$ \\
& Replacement of both hips \\
\hline
\end{tabular}


The technologist, who conducted all DXA scans, daily performed a quality assurance scan to standardize measurements. The in vivo short-term reproducibility values for the measurement of BMDs were all lower than $1 \%$ at different sites. The mean values from young Chinese men $^{13}$ were used to calculate the T-scores as reference: L1-L4, $1.017 \pm 0.117 \mathrm{~g} / \mathrm{cm}^{2}$; femoral neck $0.909 \pm 0.116 \mathrm{~g} / \mathrm{cm}^{2}$; and total hip $0.993 \pm 0.121 \mathrm{~g} / \mathrm{cm}^{2}$.

According to the WHO criteria, diagnosis of OP was determined by a BMD T-score of $\leq-2.5$ SDs at any site of L1-L4, femoral neck, or total hip sites.

\section{OSTA score}

OSTA was calculated based on age and body weight, using the following formula: ${ }^{7}$ (Body weight $[\mathrm{kg}]-$ age [years]) $\times 0.2$. As introduced in the original research, the decimal digits were then disregarded. For example, a 65-year-old man whose body weight was $62 \mathrm{~kg}$ would have an OSTA index of: $(62-65) \times 0.2=-0.6$. The decimal digit $(0.6)$ was then disregarded, and the man would have an OSTA index of 0.

\section{Statistical analysis}

Descriptive statistical analysis was used to characterize the demographic distribution of the subject. Measurement data distribution was described in mean $\pm \operatorname{SD}(\bar{\chi} \pm \mathrm{s})$ form. Constituent ratio was used for count data. Each risk factor was assessed as a predictor in univariate analysis. All statistical tests were two-sided. The statistical model was developed based on different statistically significant variables. The screening tool model was created by way of logistic regression analysis, using SPSS 19.0 (SPSS Inc., Chicago, IL, USA). The regression coefficients for age and height were stratified by increments of 10 years and $1 \mathrm{~m}$, respectively. Smoking was answered "yes" or "no" depending on whether the subject currently smoked tobacco. Alcohol consumption was scored "yes" if the subject took three or more units of alcohol daily. A drink of alcohol varies slightly in different countries from 8 to $10 \mathrm{~g}$ of alcohol. This equaled to a standard glass of beer $(285 \mathrm{~mL})$, a single measure of spirits $(30 \mathrm{~mL})$, a medium-sized glass of wine $(120 \mathrm{~mL})$, or 1 measure of an aperitif $(60 \mathrm{~mL})$. A previous fracture meant any fracture after the age of 45 years with or without low-energy trauma history. Statistical weights used in calculating the index were based on the regression coefficient in ultimate model. To calculate the index for each person, the statistical weight for enumeration data was multiplied by the patient's response (no $=0$, yes $=1$ ) and added to the total.

The comparison of the new screening tool with OSTA for identifying OP was assessed through receiver operating characteristic (ROC) curve analysis, which plots sensitivity against ( 1 - specificity). The prognostic value of the tools was identified according to the area under the ROC curve (AUC) as follows: non-predictive (AUC $<0.5$ ), less predictive $(0.5<$ AUC $<0.7)$, moderately predictive $(0.7<\mathrm{AUC}<0.9)$, highly predictive $(0.9<\mathrm{AUC}<1)$, and perfect prediction $(\mathrm{AUC}=1)$. AUC values $>0.75$ were, generally, considered to indicate good performance. ${ }^{14,15}$ The ROC curve was constructed, and AUC and its $95 \%$ confidence interval (CI) were estimated using MedCalc v11.5.0.0 software (MedCalc Software, Ostend, Belgium). A $P$-value $<0.05$ was considered statistically significant.

\section{Construction of the final model}

The differences of risk factors between OP and health groups in experiment samples for each variable were shown in Table 2. The final multivariate regression model included the following variables: age, height, weight, parent history of fractured hip, current smoking, alcohol consumption $\geq 30 \mathrm{~g} / \mathrm{d}$, and history of fracture after the age of 45 years. It was worth mentioning that BMI was not selected in the derivation of the final model. Because BMI used the combination of height and weight, it was inaccurate to take both height and weight and BMI into the construction of the index. Besides, height yielding a standard error of 0.772 was not included in the final model. Hence, the multivariate regression model included height and weight instead of BMI.

Multiple variable models were constructed starting with all variables, and then removing individual variables one at

Table 2 Summary of descriptive characteristics of the OP and health groups $(n=1,870)$

\begin{tabular}{|c|c|c|c|c|}
\hline Variable & $\begin{array}{l}\text { Osteoporosis } \\
(n=266)\end{array}$ & $\begin{array}{l}\text { Health } \\
(n=1,604)\end{array}$ & $\begin{array}{l}\chi^{2}{ }_{\text {trend }} l \\
\text { t-value }\end{array}$ & $P$-value \\
\hline \multicolumn{5}{|l|}{ Current smoking } \\
\hline Y & $14 \mid$ & 821 & 0.304 & 0.582 \\
\hline $\mathrm{N}$ & 125 & 783 & & \\
\hline \multicolumn{5}{|l|}{ Alcohol $\geq 30 \mathrm{~g} / \mathrm{d}^{\mathrm{a}}$} \\
\hline $\mathrm{Y}$ & 109 & 600 & 1.236 & 0.266 \\
\hline $\mathrm{N}$ & 157 & 1,004 & & \\
\hline \multicolumn{5}{|l|}{ Previous fracture } \\
\hline Y & 47 & 142 & 19.520 & 0.000 \\
\hline $\mathrm{N}$ & 219 & I,462 & & \\
\hline \multicolumn{5}{|l|}{ Parent fractured hip } \\
\hline Y & 12 & 92 & 0.651 & 0.420 \\
\hline $\mathrm{N}$ & 254 & 1,512 & & \\
\hline Age (year), mean \pm SD & $66.18 \pm 9.0$ & $65.29 \pm 8.8$ & 1.532 & 0.126 \\
\hline $\begin{array}{l}\text { Body mass index } \\
\left(\mathrm{kg} / \mathrm{m}^{2}\right) \text {, mean } \pm \mathrm{SD}\end{array}$ & $22.78 \pm 2.8$ & $25.25 \pm 3.0$ & 12.636 & 0.000 \\
\hline Weight $(\mathrm{kg})$, mean \pm SD & $64.25 \pm 7.9$ & $72.90 \pm 9.6$ & 13.902 & 0.000 \\
\hline Height $(\mathrm{cm})$, mean \pm SD & $|68.0| \pm 5 . \mid$ & $169.85 \pm 5.4$ & 5.199 & 0.000 \\
\hline
\end{tabular}

Notes: Data are presented as $\mathrm{n}(\%)$ or mean $\pm \mathrm{SD}$. ${ }^{\mathrm{a}}$ Taking $30 \mathrm{~g}$ or more of alcohol daily (equivalent to 3 units of alcohol in the present study).

Abbreviations: d, day; OP, osteoporosis. 
Table 3 Regression coefficients for the final multivariate model $(n=1,870)$

\begin{tabular}{llll}
\hline Variable & $\begin{array}{l}\text { Regression } \\
\text { coefficient }\end{array}$ & $\begin{array}{l}\text { Standard } \\
\text { error }\end{array}$ & $\begin{array}{l}\text { Index } \\
\text { weight }\end{array}$ \\
\hline Age (I0 years) & -0.043 & 0.645 & -0.4 \\
Height (m) & 0.426 & 0.772 & 4 \\
Weight (kg) & $0.11 \mathrm{I}$ & 0.000 & $\mathrm{I}$ \\
Previous fracture $^{\mathrm{a}}$ & -0.750 & 0.000 & -7 \\
Current smoking $^{\mathrm{b}}$ & -0.286 & $0.11 \mathrm{I}$ & -3 \\
Alcohol $\geq 3$ drinks/day $^{\mathrm{c}}$ & -0.250 & 0.875 & -3 \\
Parent fractured hip $^{\mathrm{d}}$ & -0.127 & 0.718 & -1 \\
\hline
\end{tabular}

Notes: ${ }^{a}$ Fractures after the age of 45 years; subjects answered either yes or no. bSubjects answered either yes or no depending on whether the patient currently smoked tobacco. 'Subjects answered yes if the patient takes three or more drinks of alcohol daily. A drink of alcohol varies slightly in different countries from 8 to $10 \mathrm{~g}$ of alcohol. This is equivalent to a standard glass of beer $(285 \mathrm{~mL})$, a single measure of spirits $(30 \mathrm{~mL})$, a medium-sized glass of wine $(120 \mathrm{~mL})$, or I measure of an aperitif $(60 \mathrm{~mL}) .{ }^{\mathrm{d}}$ This item asked whether the patient's mother or father had a history of hip fracture; subjects answered either yes or no.

a time, starting with the variable with the largest $P$-value, until all remaining variables were statistically significant $(P<0.05)$. Statistical weights used in calculating the index were based on the regression coefficient for each variable. The final model variables were used to calculate a single value (risk index) for each person by adding the index weights for each variable. Each variable was multiplied by the index weight before adding to the index. For example, 7 points would be subtracted if the person had fragility fracture after the age of 45 years. The regression coefficient, standard error, and index weight for each variable were shown in Table 3.

Excluding age, height, current smoking, alcohol consumption $\geq 30 \mathrm{~g} / \mathrm{d}$, and parent history of fractured hip, only weight and history of previous fracture were selected in the ultimate model based on standard error. According to this analysis, the model was finally calculated using the following formula: (Body weight $[\mathrm{kg}]$ - history of previous fracture $[$ no $=0$, yes $=1] \times 7$ ). For example, a man whose body weight was $66 \mathrm{~kg}$ with a previous fracture would have an index of: $66-1 \times 7=59$. The optimal cutoff diagnostic index value of 70 yielded a sensitivity of $84.96 \%$ and specificity of $53.49 \%$. This value was chosen by optimizing sensitivity and specificity together in a single curve, as shown in Figure 1. The new model had been named the Beijing Friendship Hospital Osteoporosis Self-assessment Tool for Elderly Male (BFH-OSTM).

\section{Results}

\section{Study population}

A total of 1,923 potentially eligible community-dwelling healthy men and 589 hospital-checkup men in Beijing were considered for participation in this study. Patients with a history of having taken antiresorptive medications or glucocorticoids, evidence of rheumatoid arthritis, a history or evidence of metabolic bone disease, or a painful hip fracture were excluded. Fifty-three and fifteen subjects were excluded in community-dwelling and hospital-checkup populations, respectively. More detailed exclusion criteria were shown in Table 1. The men comprised 1,870 communitydwelling (experiment samples) and 574 hospital-checkup (validation samples) individuals who were eligible for the analysis. All subjects conformed to the following inclusion criteria: aged $\geq 50$ years; Han Chinese nationality; residing in Beijing $\geq 20$ years; willing to participate in the study, and able to read the informed consent form. The descriptive characteristics obtained from the experiment samples $(n=1,870)$ were listed in Table 4 . The prevalence of OP (14.2\%) and osteopenia (51.8\%) was high in the studied population. Between the community-dwelling and hospitalcheckup populations, there were no significant differences in age, height, weight, and BMI. Men in the hospital-checkup population underwent similar prevalence of OP (13.9\%) and osteopenia $(51.5 \%)$ with those in the community-dwelling population $(P>0.05)$.

\section{Evaluation and comparison of BFH-OSTM and OSTA}

As shown in Figure 1, the AUC curve for the BFH-OSTM of estimating OP was 0.763 with the optimal cutoff value of 70 . The value, at which the curves of sensitivity and specificity crossed, achieved a sensitivity of $84.96 \%$ and a specificity of $53.49 \%$ in the community-dwelling population. Figure 2 showed the comparison of ROC curves between OSTA and BFH-OST in the hospital-checkup population. AUC relating OSTA to OP was 0.732 (95\% CI: $0.693-0.767, \mathrm{Z}=8.886$, $P<0.001)$ with the optimal cutoff (OSTA $=-1)$. The BFHOSTM index (cutoff $=70$ ), which performed better than OSTA $(P=0.0063)$, had a sensitivity of $89.92 \%$ and a specificity of $48.57 \%$ for identifying OP according to the WHO criteria. It should be noted that the optimal BFH-OSTM cutoff value to identify OP in the hospital-checkup population was 68 yielding a sensitivity of $79.83 \%$ and specificity of $62.20 \%$ with an AUC curve of 0.795 (95\% CI: 0.760-0.828, $\mathrm{Z}=13.515, P<0.001)$.

\section{Discussion}

OP is a chronic, progressive systemic skeletal disease with susceptibility to fracture. It has been widely recognized that OP and its consequent fracture are associated with increased morbidity, mortality, and social service expenditures. ${ }^{16}$ 

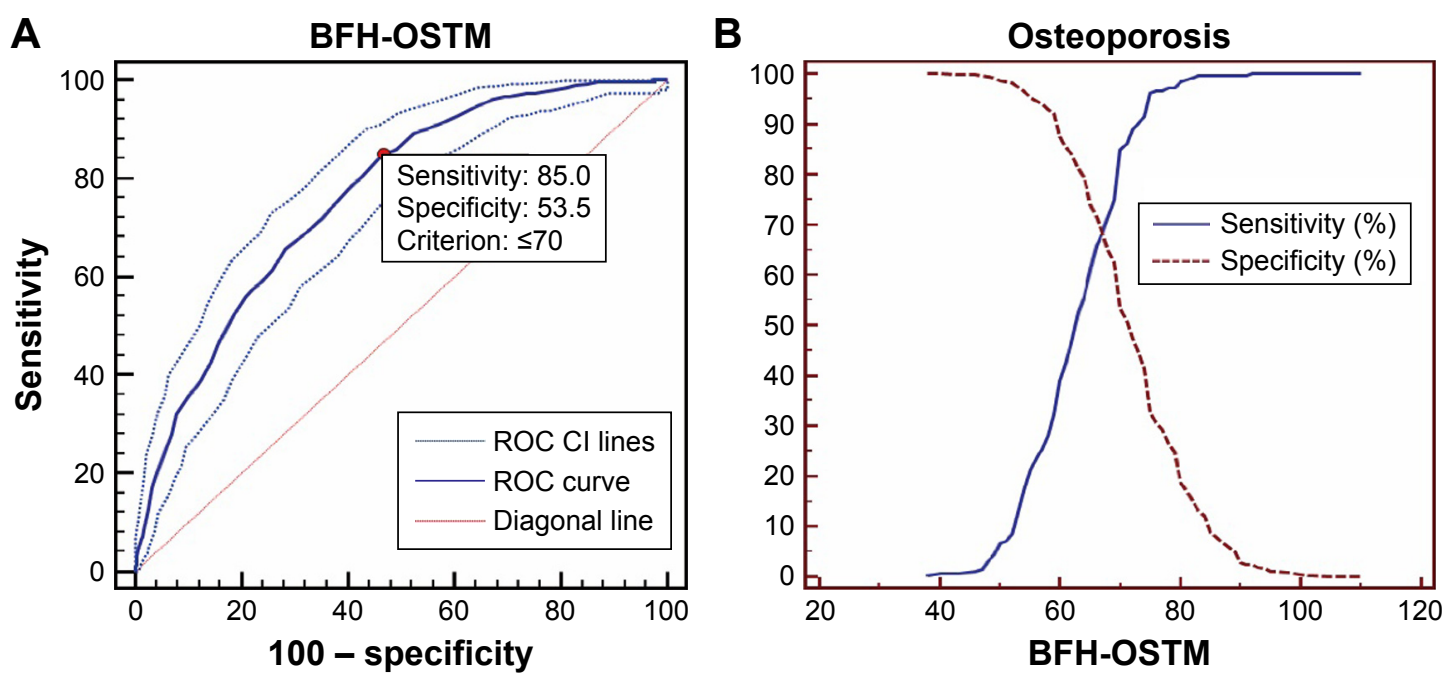

\begin{tabular}{|c|c|c|c|c|c|c|c|c|}
\hline $\begin{array}{l}\text { Golden } \\
\text { standard }\end{array}$ & AUC $(95 \% \mathrm{Cl})$ & Z-value & $P$-value & $\begin{array}{l}\text { BFH-OSTM } \\
\text { index }\end{array}$ & Sensitivity (\%) & Specificity (\%) & $+\mathrm{LR}$ & -LR \\
\hline \multirow[t]{4}{*}{ WHO criteria } & $0.763(0.743-0.782)$ & 18.234 & $<0.001$ & $\leq 91$ & 99.62 & 2.49 & 1.02 & 0.15 \\
\hline & & & & $\leq 70^{*}$ & 84.96 & 53.49 & 1.83 & 0.28 \\
\hline & & & & $\leq 55$ & 21.43 & 95.32 & 4.58 & 0.82 \\
\hline & & & & $\leq 46$ & 1.13 & 99.88 & 9.05 & 0.99 \\
\hline
\end{tabular}

Figure I ROC and sensitivity and specificity values of BFH-OSTM for diagnosis of osteoporosis (T-score $\leq 2.5$ SD) in the community-dwelling Han Chinese male population $(n=I, 870)$.

Notes: (A) AUC and (B) sensitivity and specificity values of BFH-OSTM for the diagnosis of osteoporosis $(T \leq-2.5)$ using BMD measurement. *Optimal BFH-OSTM index cutoff.

Abbreviations: AUC, area under the ROC curve; BFH-OSTM, Beijing Friendship Hospital Osteoporosis Self-assessment Tool for Elderly Male; BMD, bone mineral density; +LR, positive likelihood ratio; - LR, negative likelihood ratio; ROC, receiver operating characteristic curve; Cl, confidence interval; WHO, World Health Organization.

Table 4 Summary of descriptive characteristics of the study cohort $(n=I, 870)$

\begin{tabular}{|c|c|c|}
\hline Characteristics & Mean or value & Range \\
\hline Age (years), mean $\pm S D$ & $65.42 \pm 8.8$ & $50-90$ \\
\hline \multicolumn{3}{|l|}{ Age group (years), n (\%) } \\
\hline $50-59$ & $523 / 1,870(28 \%)$ & $50-59$ \\
\hline $60-69$ & $743 / I, 870(40 \%)$ & $60-69$ \\
\hline 70-79 & $472 / 1,870(25 \%)$ & $70-79$ \\
\hline$\geq 80$ & $132 / 1,870(7 \%)$ & $\geq 80$ \\
\hline Height $(\mathrm{cm})$, mean \pm SD & $169.59 \pm 5.4$ & $|50-19|$ \\
\hline Weight $(\mathrm{kg})$, mean $\pm \mathrm{SD}$ & $71.67 \pm 9.9$ & $40-110$ \\
\hline Body mass index $\left(\mathrm{kg} / \mathrm{m}^{2}\right)$, mean $\pm \mathrm{SD}$ & $24.90 \pm 3.1$ & $13.84-36.33$ \\
\hline \multicolumn{3}{|l|}{ BMD $\left(\mathrm{g} / \mathrm{cm}^{2}\right)$, mean $\pm \mathrm{SD}$} \\
\hline $\mathrm{LI}-\mathrm{L} 4$ & $0.996 \pm 0.16$ & $0.54 I-1.488$ \\
\hline Femoral neck & $0.798 \pm 0.13$ & $0.431-1.296$ \\
\hline Total hip & $0.916 \pm 0.13$ & $0.563-1.323$ \\
\hline \multicolumn{3}{|l|}{ T-score, mean \pm SD } \\
\hline LI-L4 & $-0.86 \pm 1.4$ & $-5.0-3.6$ \\
\hline Femoral neck & $-0.97 \pm 1.0$ & $-3.7-2.7$ \\
\hline Total hip & $-0.77 \pm 0.9$ & $-3.1-1.9$ \\
\hline \multicolumn{3}{|l|}{ WHO diagnostic categories, n (\%)* } \\
\hline Normal & $635 / 1,870(34.0 \%)$ & \\
\hline Osteopenia & $969 / 1,870(51.8 \%)$ & \\
\hline Osteoporosis & $266 / 1,870(14.2 \%)$ & \\
\hline
\end{tabular}

Note: *Lowest BMD T-score in the lumbar spine, femoral neck, or total hip was considered.

Abbreviations: BMD, bone mineral density; WHO, World Health Organization.
In this community-dwelling population, the prevalence of osteopenia and OP was $51.8 \%$ and $14.2 \%$, similar with the hospital-checkup population. This high prevalence highlights the urgent need for available screening tools to recognize men at risk for fragility fractures. Male OP is largely neglected in the whole world, especially in China. The OP group in experiment samples included 266 males, they had not realized that they suffered OP until verified by DXA. In 2008, the WHO introduced the FRAX to evaluate patients' absolute risk of osteoporotic fracture. To predict an individual's 10-year probability of major osteoporotic fractures, or for hip fracture only, FRAX considers the interaction of multiple risk factors, such as age, gender, and personal and familial history. However, few studies have proven the value of FRAX for identifying OP. Hence, a simple and effective screening tool which is useful for patients as well as for physicians with limited professional experience, used as an aide for identifying OP is urgently needed.

We developed a clinical risk assessment tool for identifying DXA-determined OP in a Han Chinese population by estimating several possible risk factors. The final index was based on weight and history of fragility fracture after the 


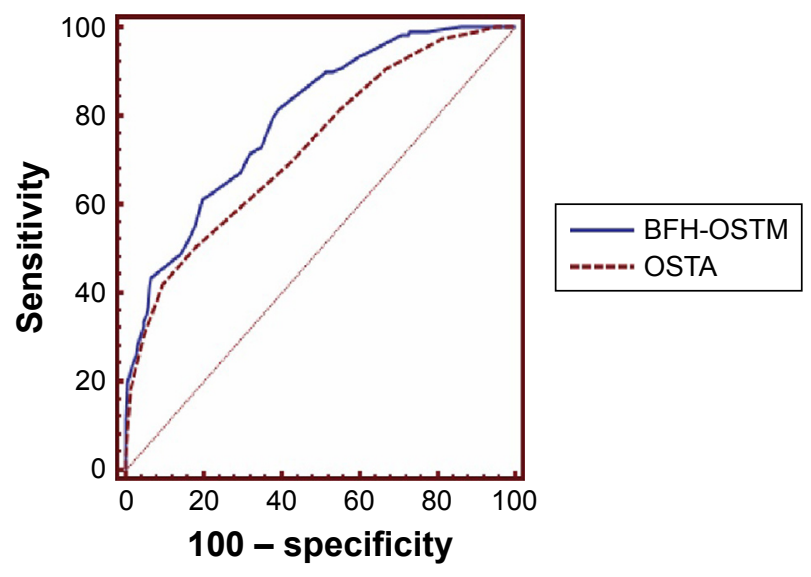

\begin{tabular}{|c|c|c|c|c|c|c|c|}
\hline $\begin{array}{l}\text { Diagnosis } \\
\text { tool }\end{array}$ & AUC (95\% Cl) & Z-value & $P$-value & Sensitivity (\%) & Specificity (\%) & Cutoff value & $\begin{array}{l}\text { Difference } \\
\text { between area }\end{array}$ \\
\hline \multirow[t]{3}{*}{ BFH-OSTM } & $0.795(0.760-0.828)$ & 13.515 & $<0.001$ & 71.43 & 68.13 & $\leq 66$ & $P=0.0063$ \\
\hline & & & & $79.83^{*}$ & 62.20 & $\leq 68$ & \\
\hline & & & & 89.92 & 48.57 & $\leq 70$ & \\
\hline \multirow[t]{3}{*}{ OSTA } & $0.732(0.693-0.767)$ & 8.886 & $<0.001$ & 42.02 & 90.55 & $\leq-2$ & \\
\hline & & & & $50.42^{\#}$ & 82.20 & $\leq-1$ & \\
\hline & & & & 69.75 & 57.58 & $\leq 0$ & \\
\hline
\end{tabular}

Figure 2 The comparison between OSTA and BFH-OSTM for diagnosis of osteoporosis ( $T$-score $\leq-2.5$ ) in the hospital-dwelling Han Chinese male population ( $\mathrm{n}=574$ ). Notes: *Optimal BFH-OSTM index cutoff; \#optimal OSTA cutoff.

Abbreviations: AUC, area under the ROC curve; BFH-OSTM, Beijing Friendship Hospital Osteoporosis Self-assessment Tool for Elderly Male; OSTA, Osteoporosis Selfassessment Tool for Asians.

age of 45 years. It was necessary to emphasize the results, which showed that there was no significant difference in age between the OP and health groups in experiment samples. Our previous research ${ }^{17}$ on community elderly male population also suggested the age may not be the most important risk factor in men compared to women for OP and related fractures in Chinese population. The data of this study was collected only from subjects recruited at a single hospital and three community health service centers and thus could not fully represent the entire demographics in China. The population structure of our study might be different from the actual demographic profile of Beijing, which could affect the generalizability of the data. It might explain why age did not appear to contribute additional information about risk. This study demonstrated that history of fracture was an important clinical risk factor for OP, which was consistent with other researches. ${ }^{18,19}$ It is possible that limb fixation and long-term bedridden may accelerate irreversible structural loss in bone microarchitecture. Several studies have examined the risk of a second hip fracture associated with a previous hip fracture. ${ }^{20-22}$

It is, generally, accepted that BMI is a protective factor against OP. A study has proven that BMI is a crucial risk factor influencing the occurrence and development of OP. Every unit increase in BMI is associated with an increase of
$0.0082 \mathrm{~g} / \mathrm{cm}^{2}$ in BMD $(P<0.001)$. A 10 -unit increase in BMI (eg, from normal BMI to obese) would result in moving an individual from an osteoporotic BMD level to a normal BMD level. ${ }^{23}$ Our study results confirm a protective, cross-sectional association between BMI and OP.

OSTA is a simple tool for assessing postmenopausal Asian women at risk of suffering OP based on age and body weight. Recently, there is a research proves that OSTA index may be a simple and effective clinical risk assessment tool for identifying the risk of primary OP as defined by DXA at femoral neck site in Chinese elderly male. ${ }^{24}$ In our study, OSTA performed not well to identify OP with an AUC of 0.732 . We supposed that age was not a risk factor for male OP in this study, which might reduce the predictive value. In addition, our results showed that OSTA had relatively low sensitivity for estimating risk of OP, while specificity was acceptable. It is not necessary that a risk assessment tool have both high sensitivity and high specificity when the tool is free and noninvasive. Because the primary purpose of the screening tool is to identify most patients at risk, among whom BMD can then be used to obtain a definite diagnosis. Therefore, a screening tool with higher sensitivity than OSTA for identifying OP is desirable.

BFH-OSTM has higher sensitivity and lower specificity to OSTA, which means that in contrast to OSTA, it may be 
more effective in screening for OP. For a safe and noninvasive screening tool, high sensitivity (a high ratio of true positives to false positives) is more important than high specificity because there is no risk of harm to the patient from unnecessary treatment or invasive diagnostic testing in the case of a false-positive result from the BFH-OSTM. Our study also suggests that the simple tool may even identify a subset of high-risk men who may be eligible for treatment even if BMD has not been measured. Of course, specificity also should be contained at reasonable levels to reduce unessential testing and the associated costs to the patient and community. The optimal value for BFH-OSTM of 70 was defined in this data set by optimizing the sensitivity and specificity. However, it will be significant to validate this cutoff in additional data sets. It will also be important to see if the BFH-OSTM accurately identifies men with OP in populations other than Han Chinese elderly male. In general, BFH-OSTM was modestly superior to OSTA, with an AUC of 0.795, and the difference was statistically significant $(P<0.05)$.

This study was community-based and cross-sectional but not retrospective, which distinguished it from previous studies. The statistics were obtained simultaneously with the BMD measurement. Furthermore, the inclusion and exclusion criteria strictly excluded the effects of secondary $\mathrm{OP}$, nationality, and any antiresorptives or anabolic medications. All the subjects were long-term residents of Beijing, and the subjects were enrolled consecutively. Besides, this analysis, which proposed a new method for identifying OP based on the WHO diagnostic classification (T-score $\leq-2.5$ at the femoral neck, total hip, or lumbar spine) for patients needing treatment.

\section{Limitations}

Similar to other studies, the present study is limited by the following conditions. First, there was a bias in the subject selection, as all the subjects were recruited from the community health service center and hospital clinic population. So, the study population might not fully represent the actual demographic situation in Beijing, which could impact the generalizability of these data. Second, self-selection of participants biased our population sample toward higher levels of education and income, which should be confirmed in other cohorts. Third, this new tool had not yet been demonstrated to predict fractures. Therefore, further investigation should be performed in a larger scale.

\section{Conclusion}

In conclusion, our study developed a new OP self-assessment tool (BFH-OSTM), which may be a simple and effective prescreening tool for identifying elderly male at increased risk for OP.

\section{Acknowledgment}

The study was funded by the Capital Health Project (Z131100006813040), Beijing, People's Republic of China.

\section{Disclosure}

The authors report no conflicts of interest in this work.

\section{References}

1. NIH Consensus Development Panel on Osteoporosis Prevention, Diagnosis, and Therapy, March 7-29, 2000: highlights of the conference. South Med J. 2001;94(6):569-573.

2. Center JR, Nguyen TV, Schneider D, Sambrook PN, Eisman JA. Mortality after all major types of osteoporotic fracture in men and women: an observational study. Lancet. 1999;353(9156):878-882.

3. Hochberg M. Preventing fractures in postmenopausal women with osteoporosis. A review of recent controlled trials of antiresorptive agents. Drugs Aging. 2000;17(4):317-330.

4. Kanis JA. Assessment of fracture risk and its application to screening for postmenopausal osteoporosis: synopsis of a WHO report. WHO Study Group. Osteoporos Int. 1994;4(6):368-381.

5. Watts NB, Lewiecki EM, Miller PD, Baim S. National osteoporosis foundation 2008 clinician's guide to prevention and treatment of osteoporosis and the world health organization Fracture Risk Assessment Tool (FRAX): what they mean to the bone densitometrist and bone technologist. J Clin Densitom. 2008;11(4):473-477.

6. Kling JM, Clarke BL, Sandhu NP. Osteoporosis prevention, screening, and treatment: a review. J Womens Health (Larchmt). 2014;23(7): $563-572$.

7. Koh LK, Sedrine WB, Torralba TP, et al. A simple tool to identify asian women at increased risk of osteoporosis. Osteoporos Int. 2001;12(8): 699-705.

8. Rud B, Hilden J, Hyldstrup L, Hróbjartsson A. Performance of the osteoporosis self-assessment tool in ruling out low bone mineral density in postmenopausal women: a systematic review. Osteoporos Int. 2007; 18(9):1177-1187.

9. Oh SM, Nam BH, Rhee Y, et al. Development and validation of osteoporosis risk-assessment model for Korean postmenopausal women. J Bone Miner Metab. 2013;31(4):423-432.

10. Su FM, Liu DH, Chen JF, et al. Development and validation of an Osteoporosis Self-Assessment Tool for Taiwan (OSTAi) postmenopausal women-A sub-study of the Taiwan OsteoPorosis Survey (TOPS). PLoS One. 2015;10(6):e0130716.

11. Canhão H, Fonseca JE, Queiroz MV. [Eating habits and life styles in a Portuguese population - protective and risk factors for osteoporosis]. Acta Reumatol Port. 2006;31(4):331-339. Portuguese.

12. Saitoglu M, Ardicoglu O, Ozgocmen S, Kamanli A, Kaya A. Osteoporosis risk factors and association with somatotypes in males. Arch Med Res. 2007;38(7):746-751.

13. Yeh LR, Chen CK, Lai PH. Normal bone mineral density in anteroposterior, lateral spine and hip of Chinese men in Taiwan: effect of age change, body weight and height. $J$ Chin Med Assoc. 2004;67(6): 287-295.

14. Swets JA. Measuring the accuracy of diagnostic systems. Science. 1988;240(4857):1285-1293.

15. Greiner M, Pfeiffer D, Smith RD. Principles and practical application of the receiver-operating characteristic analysis for diagnostic tests. Prev Vet Med. 2000;45(1-2):23-41.

16. Johnell O, Kanis JA. An estimate of the worldwide prevalence and disability associated with osteoporotic fractures. Osteoporos Int. 2006; 17(12):1726-1733. 
17. Zhang X, Lin J, Yang X, et al. [Investigation of osteoporosis prevalence and osteoporosis-related clinical risk factors among healthy elderly male]. Zhonghua Yi Xue Za Zhi. 2015;95(41):3366-3369. Chinese.

18. Fujiwara S. Epidemiological view of fracture risk. Clin Calcium. 2010;20(9):1321-1326.

19. Giangregorio LM, Leslie WD; Manitoba Bone Density Program. Time since prior fracture is a risk modifier for 10-year osteoporotic fractures. J Bone Miner Res. 2010;25(6):1400-1405.

20. Nymark T, Lauritsen JM, Ovesen O, Röck ND, Jeune B. Short timeframe from first to second hip fracture in the Funen County Hip Fracture Study. Osteoporos Int. 2006;17(9):1353-1357.

21. Chapurlat RD, Bauer DC, Nevitt M, Stone K, Cummings SR. Incidence and risk factors for a second hip fracture in elderly women. The Study of Osteoporotic Fractures. Osteoporos Int. 2003;14(2):130-136.
22. Ryg J, Rejnmark L, Overgaard S, Brixen K, Vestergaard P. Hip fracture patients at risk of second hip fracture: a nationwide population-based cohort study of 169,145 cases during 1977-2001. J Bone Miner Res. 2009; 24(7):1299-1307.

23. Lloyd JT, Alley DE, Hawkes WG, Hochberg MC, Waldstein SR, Orwig DL. Body mass index is positively associated with bone mineral density in US older adults. Arch Osteoporos. 2014;9:175.

24. Yang Y, Li D, Fei Q, et al. Self-assessment tool to identify primary osteoporosis in Chinese elderly males. Int J Gerontol. 2015;9(2):71-76.
Clinical Interventions in Aging

\section{Publish your work in this journal}

Clinical Interventions in Aging is an international, peer-reviewed journal focusing on evidence-based reports on the value or lack thereof of treatments intended to prevent or delay the onset of maladaptive correlates of aging in human beings. This journal is indexed on PubMed Central, MedLine,

\section{Dovepress}

CAS, Scopus and the Elsevier Bibliographic databases. The manuscript management system is completely online and includes a very quick and fair peer-review system, which is all easy to use. Visit http://www.dovepress. com/testimonials.php to read real quotes from published authors. 